\title{
nature
}

nanotechnology

\section{Location, location, location}

\author{
Although the number of nanotechnology papers published by Chinese researchers is \\ increasing rapidly, the US and Europe continue to lead in terms of quality.
}

By the time this article goes live on the web Nature Nanotechnology will have published 94 letters and 55 articles reporting the results of original research carried out at laboratories around the world. Browsing through the different subject categories in the journal's archive, it can be seen that the most popular categories include 'electronic properties and devices' and 'nanobiotechnology'. Further browsing will give the clear impression that researchers from the United States dominate the world of nanotechnology, with a number of countries vying for second place, quite some way behind. Indeed, when the papers published so far in Nature Nanotechnology are classified according to the country in which the corresponding author was based at the time, we find that $47.6 \%$ of them come from the US, followed by $8 \%$ from the UK, 7.4\% from Japan and 6.7\% from Germany.

Classifying papers according to the affiliation of the corresponding author is clearly an approximation, but given the fact that papers can contain ten or more authors with affiliations in three or more countries, it is necessary to make such approximations if we want to understand which areas of the world are strongest in nanoscience and technology. Indeed, a recent study of a much larger sample of nanotechnology papers found that this 'first-author approximation' was fairly reliable ${ }^{1}$.

In this study Jan Youtie and co-workers analysed nanotechnology publications and citations for four countries (China, Germany, Japan and the US), the EU27 (which, obviously, includes Germany among its 27 member states), and the Asian Tigers (Singapore, South Korea and Taiwan). The EU27 tops the list when these regions are ranked by number of authors ( $31 \%$ of the total in 2005) and number of first authors (26.4\%), followed by the US and China. However, as the authors of the study point out, it is notable that the difference between the percentages for all authors and for first authors is much smaller for China (17.6\% versus $16.5 \%)$ than for the EU27, US, Japan and Germany. This suggests that Chinese researchers are less likely than other researchers to be co-authors on papers with first authors outside their home region.

\section{China is expected to overtake the US in annual output.}

So how does one collect this data in the first place? The first challenge is to compile a list of nanoscience and technology papers, which is more difficult than it appears. Some journals - such as Nanotechnology, Nano Letters, Small, Nature Nanotechnology and a number of others - only publish nano papers. However, nano papers also appear in a large number of other journals Advanced Materials, Angewandte Chemie, Applied Physics Letters and so on through the alphabet. Youtie et al. used what they describe as a 'two-stage modularized Boolean approach' to compile their list ${ }^{2}$. The first stage involved searching on eight character strings including 'nano ${ }^{*}$ ' and variants on other terms such as 'quantum', 'self-assembly' and 'microscopy', and a second stage removed papers that were not relevant (for example, because the use of the nano* search term returned papers containing chemical formulae for $\mathrm{NaNO}_{2}$ or $\mathrm{NaNO}_{3}$ ). Their final database contained some 406,000 papers published between 1990 and the middle of 2006.
The results show that the EU27 published the most papers (just over $140,000)$ during this period, followed by the US (about 110,000) and then China (just over 50,000). More relevant, however, is the fact that China's annual output of nano papers rose to almost $20 \%$ in 2006 , just behind the US (24\%) and the EU27 (31\%). Given the rate at which China's output has been growing, it is expected to overtake the US in annual output very soon, if it has not done so already.

Of course, counting papers is a measure of quantity or output rather than quality or importance or influence. Here the news is not so good for China, and although there are signs that quality — as measured by citations - is improving, there is still a long way to go. By mid-2006 China, for instance, had only accumulated about half the number of citations of Japan, despite having published slightly more nano papers since 1990 . There is also scope for the EU27 to improve quality: although Europe overtook the US in the mid-1990s in terms of total output, the US is still well ahead in total number of citations (roughly 1.5 million compared with 1.2 million). Of course, older papers have had more time to accumulate citations, which will favour the US and disadvantage China in such comparisons. Youtie et al. use 'aged citations' (which involves dividing the number of citations for a given year by the number of years during which they could have been cited) to allow for more meaningful comparisons. However, these just confirm the need for China to focus on quality rather than quantity.

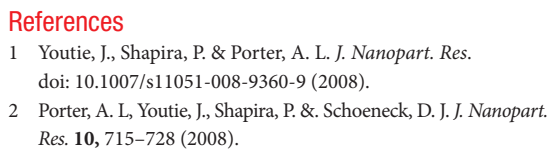

